Case Report

\title{
Review of the Literature: Organ of Giraldes Epididymal Appendage Presenting as a Painless Scrotal Mass in a 19-Year-Old Male-A Rare Urologic Entity
}

\author{
Mohamad-Fadi Dalati, ${ }^{1}$ Tania Oliveira-e-Silva, ${ }^{2}$ and Kim Entezari ${ }^{1}$ \\ ${ }^{1}$ CHU Saint-Pierre, 1000 Brussels, Belgium \\ ${ }^{2}$ Department of Urology, CHU Saint-Pierre, 1000 Brussels, Belgium \\ Correspondence should be addressed to Mohamad-Fadi Dalati; dalati_fadi@yahoo.be
}

Received 30 August 2015; Accepted 4 October 2015

Academic Editor: Elijah O. Kehinde

Copyright (C) 2015 Mohamad-Fadi Dalati et al. This is an open access article distributed under the Creative Commons Attribution License, which permits unrestricted use, distribution, and reproduction in any medium, provided the original work is properly cited.

An incidental finding of a testicular mass in young male population is always a case of great concern for the patient and controversy for the physician. Differential diagnosis ranges from acute scrotum (notably testicular torsion), to acute inflammation and infection, all the way to testicular tumors. We present a case of an incidental finding of a painless testicular solid mass in a 19-year-old male patient, with an end pathological result of paradidymis (organ of Giraldes) following orchiectomy. To the best of our knowledge, this is the first case of its kind to be reported in the literature.

\section{Introduction}

A testicular appendage is a vestigial residual of the Wolffian (mesonephric) duct or the Mullerian (paramesonephric) duct. A Mullerian-inhibiting substance produced during fetal growth causes the degradation of the Mullerian duct, in a craniocaudal fashion [1]. There are 5 testicular/epididymal appendages described in literature. Figure 1 illustrates the anatomical position of these appendages [2]. The first and the most cranial part develops into the appendix testis, also known as the sessile hydatid of Morgagni. Next in order originating from the head of the epididymis is the appendix epididymis. The third appendage is the paradidymis, also known as the organ of Giraldes (Par), which attaches to the lower spermatic cord, and is gaining an origin from the Wolffian (mesonephric) duct, mainly from its caudal portion. Originating from the body of the epididymis is the cranial aberrant duct, also called the cranial vas aberrans of Haller $(*)$, which also originated from the Wolffian duct. Finally at the level of the tail of the epididymis, we have the caudal vas aberrans of Haller $(*)$. Pathologies and cases involving these appendages are quite rare and almost always involve a presentation of an acute scrotal mass.

\section{Case}

We describe a case of a healthy 19-year-old male patient, presenting to the urology clinic for an incidental finding of a painless left scrotal mass. Clinical history goes back to a couple of days before, where the patient first noticed a mass while taking a shower. The patient denies recent scrotal trauma, unprotected sexual intercourse, penile discharge, urinary symptoms, fever, or chills. Physical exam revealed a 3$4 \mathrm{~cm}$ scrotal mass, attached to the left testicle at the level of the epididymis. The mass was painless to palpation and mobile with the testicle. No inguinal hernia or inguinal lymph nodes were detected during the physical exam. Both testicles were of normal size and position. Cremasteric reflex was present bilaterally. No signs of inflammation, edema, erythema, or infection were observed. Blood and urine exams were within normal ranges, including hemoglobin, $\mathrm{Hb}$, hematocrit, Hct, white blood cells, WBC, C-reactive protein, CRP, negative red blood cells, RBC, and white blood cells, WBC, in urine and negative urine culture. Tumor markers (alpha fetoprotein, AFP, $\beta$-HCG, and lactate dehydrogenase, LDH) were also negative. Ultrasound of the scrotum paradoxically revealed 


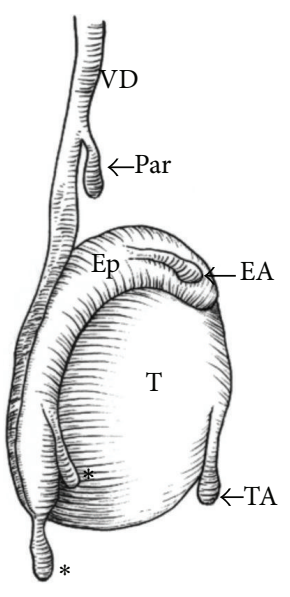

FIgURE 1: Testicular appendages; VD: vas deferens; T: testicle; Ep: epididymis; Par: organ of Giraldes; EA: epididymal appendage; TA: testicular appendage; $*$ : aberrans of Haller. Source: Favorito et al. [2].

a swelling of the left epididymis and the testicle with hypervascularization signals on Doppler ultrasound suggestive of epididymitis.

The decision was made to treat the subclinical, ultrasound-evident epididymitis with a course of fluoroquinolones (ciprofloxacin). Two weeks later, physical exam showed similar findings to the one done two weeks ago, and testicular ultrasound showed a $3 \mathrm{~cm}$ testicular swelling, with similar Doppler findings.

This atypical presentation of a painless scrotal mass in a young male adult, with negative tumor markers and ultrasound suggestive of epididymitis in the absence of any inflammatory signs or symptoms, with no signs of improvement with a course of antibiotics, as well as the risk of malignant lesion, put a remarkable amount of stress on the patient and the treating team, resulting in a decision to go for surgical testicular exploration via an inguinal incision due to the risk of testicular malignancy. Metastatic workup was composed of fluorine-18-fluorodeoxyglucose positron emission tomography ${ }^{18}$ F-FDG PET-CT, showing a hypermetabolic lesion of the left testicle, with iliac and paraaortic lymphadenopathy.

During surgery, the left testicle was delivered via an inguinal incision. Dissection of the mass off the testicle was tried, but due to the adherent nature of the mass to the testicle itself, increasing the risk of malignancy, the final decision was made to undergo a total left radical orchiectomy. Patient was discharged the following day.

Pathology report showed a normal testicle $(6.5 \times 4 \times$ $3.7 \mathrm{~cm}$ ), spermatic cord, and an epididymis containing an indurated whitish lesion, measuring $3.5 \times 2 \times 1.6 \mathrm{~cm}$. No histological anomalies of the testicle were noted. A significant inflammatory remnant of the epididymis was reported, with microabscess in vestigial remnants (Figures 2 and 3 ).

A cystic structure with no obvious continuity with the epididymis was also noted, bordered by a pseudostratified

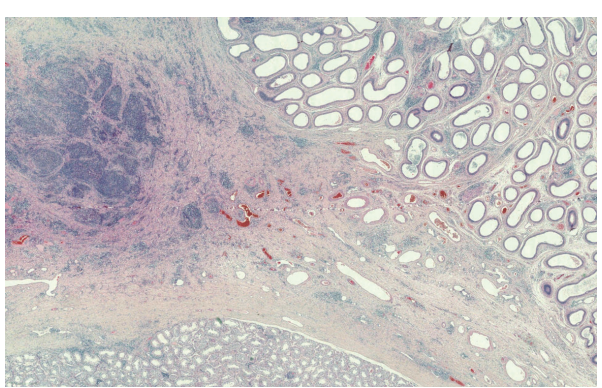

FIGURE 2: Testicular parenchyma in the bottom, epididymis in the upper right, and inflammatory vestigial remnants in upper left.

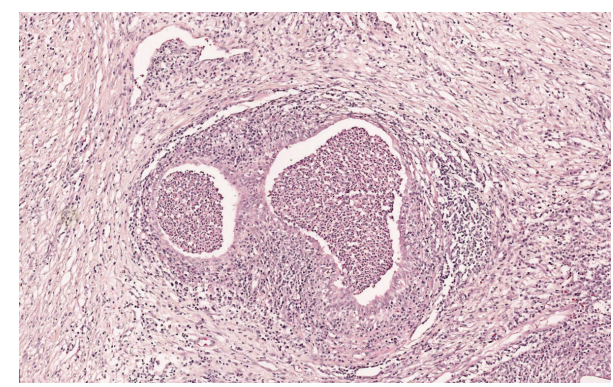

FIgURE 3: Microabscess in vestigial remnants.

epithelium without tumoral cellular atypia, consistent with organ of Giraldes, with no sign of malignancy.

${ }^{18}$ F-FDG PET-CT was repeated 2 months after surgery and showed complete remission of the previously hypermetabolic picture that was reported in the previous imaging.

\section{Discussion}

In a study by Sahni et al. [3], the incidence of epididymal appendage in adults on autopsy was estimated to be around $20 \%$. In another study by Favorito et al. [2], the incidence of epididymal appendages was $14.5 \%$ in the cryptorchidism group and $8.4 \%$ in the control one, with no statistically significant difference between the two groups. The organ of Giraldes as a cause of a scrotal mass is a very rare pathologic finding, with cystic transformation and torsion being the most common presentation. It is usually located in the anteroinferior portion of the spermatic cord, varying in size, with no direct relationship to the epididymis or the testicle. Diagnosis is very challenging, almost always done only after surgical excision. Ultrasound of the scrotum and Doppler ultrasound for assessment of testicular perfusion fail to confirm the diagnosis and are often inconclusive.

There are no studies indicating risk of malignancy of these appendages, nor there were, to the best of our knowledge, any case reports of a painless scrotal mass, which was surgically explored, turning out to be an appendage.

Torsion of the appendages, mainly in adolescents, remains to be a risk to consider. Van Glabeke et al. described 543 cases of acute scrotum pain in boys aged between 1 and 16 years, resulting in surgical exploration [4], of which $46 \%$ 
TABLE 1: Summary of studies describing testicular and epididymal appendages.

\begin{tabular}{lcc}
\hline Study & Incidence of appendages & Incidence after surgical exploration (acute scrotum) \\
\hline Sahni et al., 1996 [3] & $20 \%$ \\
\hline Favorito et al., 2004 [2] & $\begin{array}{c}14.5 \% \text { in cryptorchidism } \\
8.4 \% \text { in control }\end{array}$ \\
\hline Van Glabeke et al., 1999 [4] & $46 \%$ torsion of appendages \\
\hline Puri and Boyd, 1976 [5] & 22 cases \\
\hline Khairi et al., 2007 [6] & & $20.5 \%$ torsion of appendages \\
\hline Çavuşoglu et al., 2005 [7] & $32.3 \%$ torsion of appendages \\
\hline
\end{tabular}

were due to torsion of appendages. Puri and Boyd [5] stated that torsion of testicular/epididymal appendages is very rare after the age of 20 years because of what they referred to as "local fibroses." Their study reported 22 cases of torsion of testicular/epididymal appendages. In a retrospective study done by Khairi et al. [6], and over a period of 7 years, 34 cases of acute scrotum were managed by surgical exploration, of which 7 cases $(20.5 \%)$ were testicular/epididymal appendages torsion. In Turkey, a study by Çavuşoglu et al. [7], 32.3\% of cases of acute scrotum, managed by surgical exploration, were testicular/epididymal appendages. Table 1 summarizes these findings.

While the usage of ${ }^{18}$ F-FDG PET-CT is controversial in testicular cancer diagnosis according to the guidelines of the European Association of Urology, there are many studies in the literature favoring its usage. A meta-analysis done by Zhao et al. [8] examined a total of 16 studies, with a total number of patients up to 807 and $957{ }^{18}$ F-FDG PET exams. The meta-analysis showed sensitivity of $87 \%$ and specificity of $75 \%$. It concluded that combining CT with FDG-PET is potentially a useful tool in diagnosis of testicular cancer, while admitting the low specificity of such imaging technique. In our hospital, we use ${ }^{18} \mathrm{~F}$-FDG PET-CT in the metastatic workup before surgical exploration, as well as during followup cycles.

Even though surgical excision is theoretically not mandatory in case of testicular and epididymal appendages, due to the benign nature of these structures, with no signs of torsion, the burden of a solid scrotal mass in young males associated with the risk of testicular malignancy, even in the absence of elevated tumor markers or suspicious features of ultrasound, challenges both patient and urologist and drives management towards surgical exploration and excision.

In our opinion, the classic approach to scrotal masses in young male population, including physical exam, scrotal ultrasound, and tumor markers (AFP, $\beta$-HGC, and LDH), cannot give a clear contribution for the diagnosis of organ of Giraldes, leaving surgical exploration and eventually orchiectomy a must-do approach. Our case represents a rare entity in the literature, of a solid scrotal mass, with no other associated symptoms, ending up with surgical exploration and orchiectomy for the suspicion of testicular cancer, with an end result of organ of Giraldes. We believe that solid masses, even in the absence of supporting diagnostic measures, should be managed by surgical exploration and confirmation of absence of malignancy by pathology.

\section{Disclosure}

The authors confirm that they have given due consideration to the protection of intellectual property associated with this work and that there are no impediments to publication, including the timing of publication, with respect to intellectual property. In doing so the authors confirm that they have followed the regulations of their institutions concerning intellectual property.

\section{Conflict of Interests}

The authors wish to confirm that there is no known conflict of interests associated with this work and there has been no significant financial support for this work that could have influenced its outcome.

\section{Authors' Contribution}

The authors confirm that the paper has been read and approved by all named authors and that there are no other persons who satisfied the criteria for authorship but are not listed. The authors further confirm that the order of authors listed in the paper has been approved by all of them.

\section{References}

[1] M. Maizels, "Normal and anomalous development of the urinary tract," in Campbell's Urology, P. C. Walsh, A. B. Retik, E. D. Vaughan Jr., and A. J. Wein, Eds., pp. 1545-1600, W.B. Saunders Company, Philadelphia, Pa, USA, 7th edition, 1998.

[2] L. A. Favorito, A. G. L. Cavalcante, and M. A. Babinski, "Study on the incidence of testicular and epididymal appendages in patients with cryptorchidism," The International Brazilian Journal of Urology, vol. 30, no. 1, pp. 49-52, 2004.

[3] D. Sahni, I. Jit, K. Joshi, and Sanjeev, "Incidence and structure of the appendices of the testis and epididymis," Journal of Anatomy, vol. 189, no. 2, pp. 341-348, 1996.

[4] E. Van Glabeke, A. Khairouni, M. Larroquet, G. Audry, and M. Gruner, "Acute scrotal pain in children: results of 543 surgical explorations," Pediatric Surgery International, vol. 15, no. 5-6, pp. 353-357, 1999.

[5] P. Puri and E. Boyd, “Torsion of the appendix testis," Clinical Pediatrics, vol. 15, no. 10, pp. 949-950, 1976.

[6] A. Khairi, N. El-Kholi, K. Ashour, M. Abd El-Azim, and M. Sami, "Acute scrotum in children; should all testes still be 
explored?” Annals of Pediatric Surgery, vol. 3, no. 2, pp. 97-101, 2007.

[7] Y. H. Çavuşoglu, A. Karaman, I. Karaman et al., "Acute scrotum etiology and management," Indian Journal of Pediatrics, vol. 72, no. 3, pp. 201-203, 2005.

[8] J.-Y. Zhao, Y.-Y. Li, B.-L. Zhang, M.-M. Li, X.-L. Ma, and L. Liu, "Diagnostic accuracy of 18F-FDG-PET in patients with testicular cancer: a meta-analysis," Asian Pacific Journal of Cancer Prevention, vol. 15, no. 8, pp. 3525-3531, 2014. 


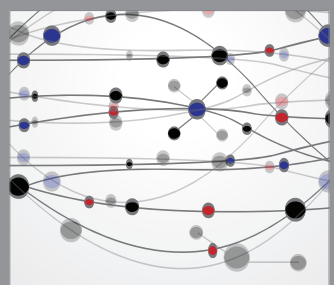

The Scientific World Journal
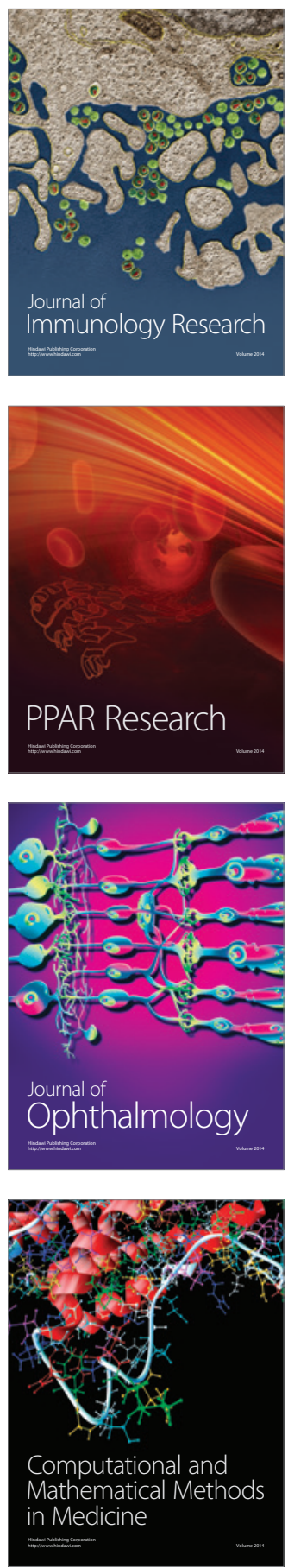

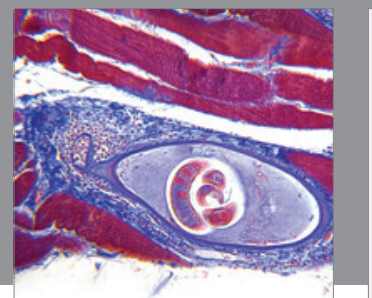

Gastroenterology

Research and Practice
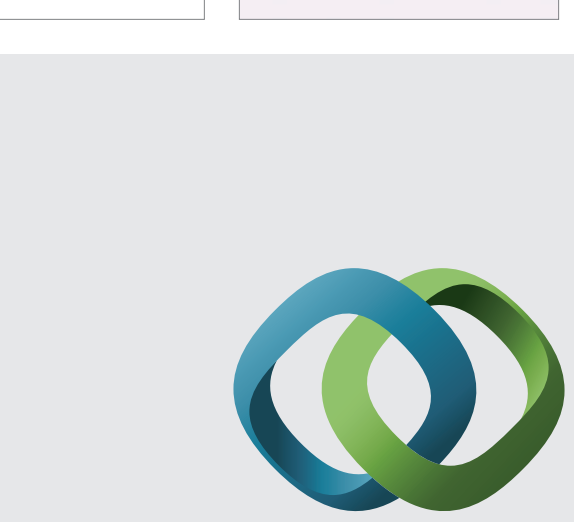

\section{Hindawi}

Submit your manuscripts at

http://www.hindawi.com
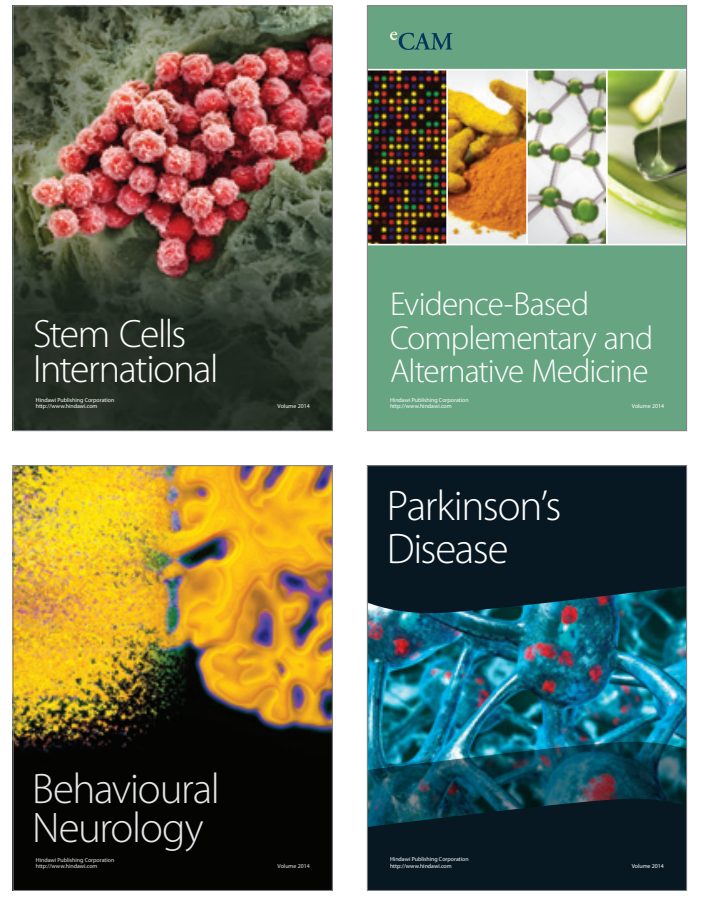
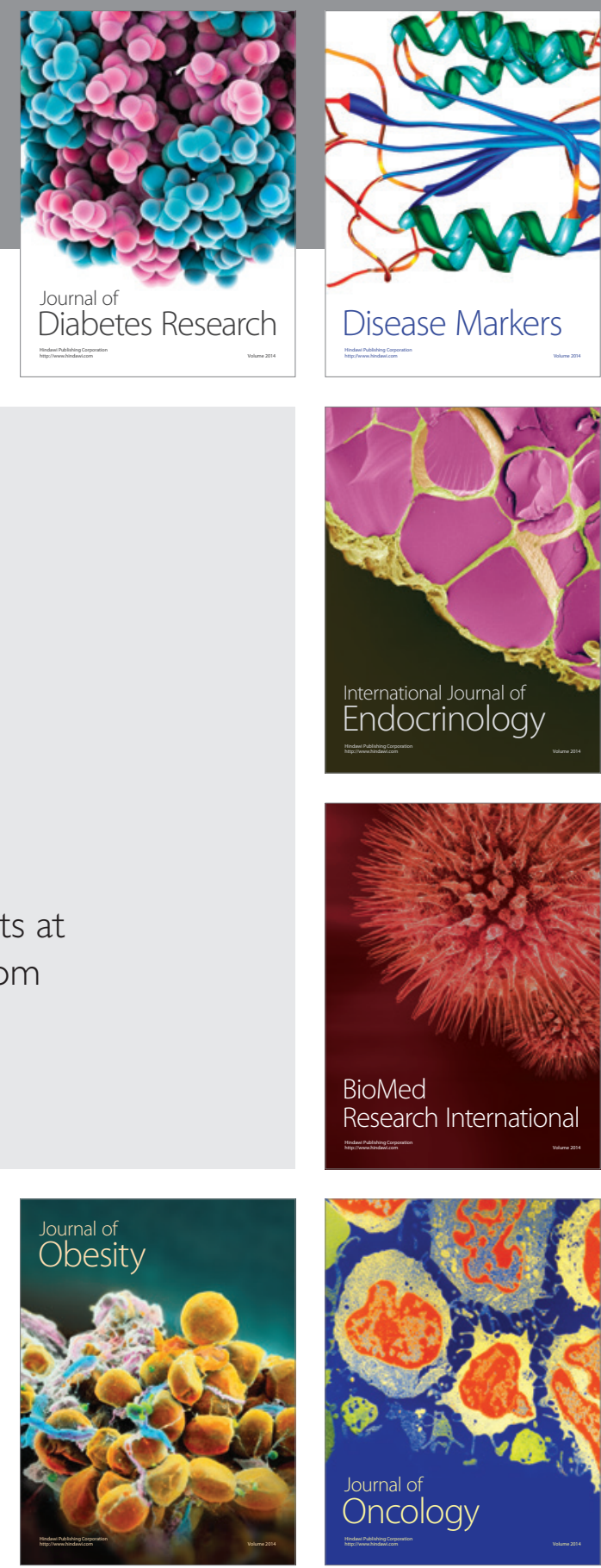

Disease Markers
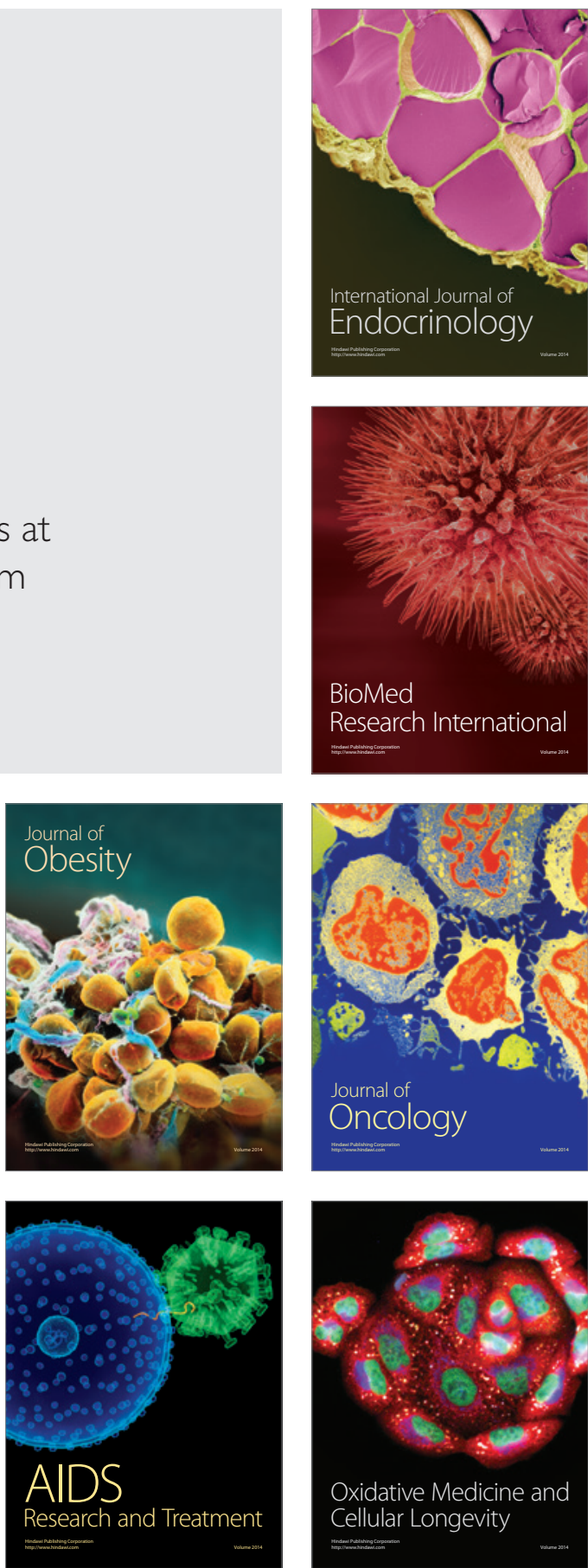